Department for Innovation, Universities \& Skills

\title{
The Role of
}

Further Education

Colleges in

Preventing Violent

Extremism: Nest Steps 


\section{Contents}

Ministerial foreword $\quad 3$

Foreword from the Champion Principals group $\quad \mathbf{5}$

Executive summary $\quad \mathbf{6}$

Introduction $\quad \mathbf{7}$

Background $\quad 9$

$\begin{array}{ll}\text { Support } & 10\end{array}$

$\begin{array}{ll}\text { Next steps } & 13\end{array}$

Annex: Key contacts - Champion Principals 14 


\section{Ministerial foreword}

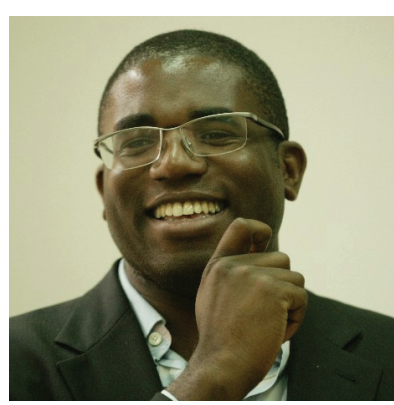

Further Education colleges are typically leaders in their community. Not just in education but as institutions that can drive economic development and regeneration through their presence, participation and leadership. While their core role is to develop the talent and innovation capacity of this country, the focus must extend beyond the purely vocational and include the ability to engage with the social challenges our society faces.

This brings a responsibility for colleges to engage with some of the more challenging aspects of community life. In some areas, this can include working with communities to develop resilience to those ideologies that promote hatred and violence. For example, colleges can find themselves in communities where the far right has significant influence and seeks to use the college to promote racial hatred and intolerance. In other cases, we know that violent extremists have actively sought to influence and recruit people through targeting learners in colleges and universities.

Our central challenge is to strengthen the resilience of communities against forces that would tear them apart, enabling them to resist extremist influence and root out terrorism, at the same time as preserving the freedom we value so much and that defines our traditions. Colleges are playing an increasingly important role in this work.
Absolutely key to this effort is our quest to develop our sense of shared values: the values that bind communities together. These values belong to everyone in Britain; they are not possessed by any one race, creed or nationality. The Further Education sector's task is to foster these values in their institutions. Shared values are experienced, not taught. They are built over time, by people sharing ideas, tolerating other views and having constructive disagreement.

Further Education provides students with skills they will draw on for the rest of their lives. Since many people pass through Further Education at some point it is absolutely critical that institutions embody these values of openness, free debate and tolerance, and promote them through the way they operate.

By promoting this culture, we will provide an environment with trust and respect in which communities can deal more productively and collaboratively with any conflict arising from differences of culture, ideology or faith. It will also enable us to seek to convince, via rational argument, those who hold the sorts of extremist tendencies that are the enemies of rational argument. We prize academic freedom and freedom of speech as ends in themselves and as the most effective way of challenging the views which we may find abhorrent but that remain within the law. 
Institutions have a responsibility to protect all their students and staff from those who seek to exploit the freedom that education provides in order to promote violence, incite hatred, intimidate or bully others. They also have a responsibility to support all of their students, particularly those who may be at risk. Many colleges are already doing this, and for that we praise them.

We should never overstate the menace we face from violent extremism. There is a real and serious threat, and we must all take responsibility for protecting ourselves. The Government's assessment is that the greatest current threat is from Al-Qaida influenced terrorism. Freedom belongs to people, not governments. And there is no freedom at all if people face disruption and violence in their daily lives.

In February last year we consulted the sector on the particular contribution of colleges and other FE providers to preventing violent extremism and, more widely, strengthening community cohesion. This has provoked a rich and varied debate, in which many have engaged. The majority of respondents agreed that colleges and other Further Education providers do have an important role to play in combating these threats, where they arise, working in partnership with local authorities, the police and other community partners. Whilst respondents were clear that this should include all groups - Al-Qaida, the far right, and animal rights - they recognised that the scale and nature of the threat from each of these varied immensely.

Already, the sector has demonstrated considerable leadership in responding swiftly but sensitively to these issues, working with the relevant authorities and the affected communities in a sensitive and productive way - one that builds on rather than destroys the strong and supportive relationships that already exist.

Indeed, one of the key messages from the responses was that colleges want to offer an environment where freedom of speech and challenging debate are possible and where threats to this, or to the safety of individuals from extremist groups, are not tolerated. At the same time, however, colleges said that they would welcome more practical support on how they actually managed these situations.

That is why we have focused this document on setting out some of the resources and tools available to the sector to help navigate this hugely complex and difficult area. In doing so, we have deliberately drawn on the expertise that already exists. And, to further support this work, I have been hugely encouraged by the advice provided by the Champion Principals group which is looking in detail at how the sector can be encouraged and helped in responding to this agenda.

Clearly, this issue will not affect all colleges and all communities in the same way. We therefore want to develop a differentiated approach to engaging with and supporting the sector that recognises and reflects these differences... albeit that we will expect all colleges and providers to remain vigilant through dialogue with local partners so they are able to recognise individuals genuinely at risk rather than relying on stereotypes.

I hope you will all read this document and reflect on what it means for you in your particular setting and find ideas of practical steps that you could take. 


\section{Foreword from the Champion Principals group}

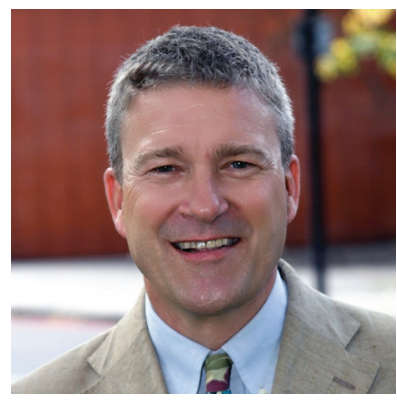

\section{Paul Head, Principal of College of North East London, on behalf of the Community Cohesion and Preventing Violent Extremism Champion Principals Group}

The Champion Principals group consists

of a set of Principals, supported by the AoC, 157 Group and LSIS, who are keen to build a greater awareness of the potential contribution that the FE college sector can make to promoting community cohesion and preventing violent extremism in all its forms.

We all have personal experience that has highlighted that these issues cannot and must not be ignored and are committed to giving our time to support others in the sector who are facing challenges in these areas.

Our first meetings have proved that we can quickly find a common understanding of the importance and value of giving time and attention to this work and the value of sharing different approaches and putting our collective minds to what is a particularly challenging issue facing our sector at this time.

Our intention is to work with the Departments and our sector bodies to ensure that the sector gets the best support it can to minimise the risk that students in an FE college get involved in violence and terrorism. We welcome suggestions and comments from colleagues across the sector. If you would like to get engaged in this, please write to the Group at s.din@bradford.ac.uk 


\section{Executive summary}

\begin{abstract}
1 This report describes how we will take
1 forward support for Further Education colleges in preventing violent extremism, following our recent consultation. These areas are complex and challenging and we do not propose to develop and issue a final set of guidance but seek to identify the support that colleges need and encourage a sector-led response to the challenge. In the consultation, colleges accepted the particular need to focus on Al-Qaida related activity but also stressed the importance of adopting approaches that will also enable them to counter incidences of extremism from other groups - most notably the far right. We believe the five objectives described in the consultation document provide a useful framework for colleges and other providers to use across a wide range of local contexts and settings. In doing this it will be particularly important that colleges' work is co-ordinated alongside that of local partners also working on Preventing Violent Extremism.
\end{abstract}

The main arrangements we have put in $\checkmark$ place to support colleges in this area:

we have established a Champion Principals group to oversee a programme of support and provide advice to Government, including making themselves available to those working in colleges if they face particular situations and need some advice;

the Learning and Skills Improvement Service (LSIS) have brought together support materials in an accessible format, within the Excellence

\section{Gateway ${ }^{1}$;}

we are providing more focused support for colleges engaged in preventing extremism through a Prevent Toolkit;

the Champion Principals group and LSIS are organising a Prevent Seminar in April 2009 for colleges to talk through the practical issues of this work;

additional Home Office resource is being provided for police forces in priority areas to enable them to build stronger partnerships with local schools, colleges and universities and the Association of Chief Police Officers have distributed guidance emphasising the importance of police entering into an ongoing dialogue with staff and students in colleges;

cross-Government guidance was published in June 2008 for local partners on the Prevent agenda which acknowledges the role of colleges.

3 . Government is providing funding to local authorities 'to disrupt radicalisers and support vulnerable individuals at a local level' and colleges should discuss with their local authority partners whether they intend to put in bids for any of these funds and explore how they could contribute to local projects.
Further work will be developed in I coming months including a review of how colleges can do more to promote tolerance, research by the Institute of Community Cohesion, and Becta guidance on how colleges can support the safety of their students in the way they manage and provide IT services.

\section{1 http://excellence.qia.org.uk/ communitycohesion}




\section{Introduction}

$\square$ This report describes how we will

$\checkmark$ take forward support for Further Education (FE) colleges in preventing violent extremism, following our recent consultation. It accompanies the report of the consultation responses.

The focus is on FE colleges rather than other providers, as the consultation showed that this is where we need to focus our attention. There are other FE provider organisations that may well be able to contribute and we anticipate that the resources being developed will be of value to them also and that, within an area, they should consider how they can work in partnership on this agenda.

7 The areas of community cohesion are complex and challenging; and they continue to change. As such, we do not propose to develop and issue a final set of guidance but rather seek to build an ongoing process of engagement which identifies the support that colleges need and encourages a sector-led response to developing and disseminating this.

The response to our consultation has shown that whilst universal action to strengthen communities in general and the prevention of violent extremism are closely linked, they are two separate agendas which need to be considered discretely.

Colleges are essential to delivering this government's commitment to engaging and helping those who are most excluded from education, the labour market and society. Many colleges already do this, in a myriad of ways: giving people the language skills they need to participate as active citizens; helping them develop the skills they need to enter the workforce; and encouraging them to progress further so they can truly unlock their talents. We believe that colleges are important agents of social change - helping individuals to succeed and progress but also engaging the hardest to reach, helping to build strong and inclusive communities. Physically, colleges are a key part of the fabric of local communities; providing an important resource and, often, landmark for local people. In particular, colleges actively engage in community cohesion work in a wide variety of ways.

1 However, as the consultation identified, there is a particular need for support for colleges in helping them to navigate their way sensitively through the challenges raised in relation to preventing violent extremism. Colleges recognise the importance of this particular area but are very concerned to ensure they get their role right. Many were concerned about 'saying the wrong thing' and were very aware of the risks that their actions or communications might have in terms of alienating members of their local communities.

\section{Colleges accept the particular need to focus on Al-Qaida related} activity but also stressed the importance of adopting approaches that will also enable them to counter incidences of extremism from other groups - most notably the far right.

12 Clearly, colleges are not on their own in responding to this agenda. They are part of local partnerships with local authorities, the police, schools, universities and community groups who are working together to address the issues that enable extremism to flourish; 
acting swiftly when this manifests itself as a real or perceived threat. Local 1419 Partnerships will be particularly important in this regard. We have sought, where possible, to identify and adopt the resources that have been developed across government recognising that, at times, there will be a need for support that is more specifically tailored to FE.

13 coll Colleges also stressed the need to integrate actions to prevent extremism with other existing arrangements - in particular mechanisms for general risk management and safeguarding of young people.

14 We also recognise that, for many issues that they need to tackle on a daily basis - in particular, dealing with knife or gang crime. We have no intention to create a hierarchy of importance of these - rather we would recognise that both present difficult challenges for the sector to deal with, and believe that colleges, working in partnership with others locally, will be best placed to identify and respond to the most relevant challenges. Action against one should help rather than undermine action to address the other.

15 dire This guidance has been sent directly to college Principals and we expect management to consult with their staff, the unions and students as appropriate in designing and implementing policies and procedures. We would expect institutions to consult widely and use collective bargaining when implementing this or any other guidance issued to them by the Department or the Funding councils. 


\section{Background}

16

In February 2008 we launched a

public consultation on the role of

FE providers in promoting community cohesion, fostering shared values and preventing violent extremism. This was part of a Government-wide initiative to develop a robust counter-terrorism programme - CONTEST.

\section{Government's counter- terrorism strategy ${ }^{2}$,} CONTEST, has four strands:

the Pursue strand is focused on disrupting terrorists and their operations;

the Protect strand of work is focused on reducing the vulnerability of the UK and UK interests overseas;

the Prepare strand is concerned with ensuring that the UK is as ready as it can be for the consequences of a terrorist attack;

the Prevent strand is focused on stopping people becoming or supporting terrorists or violent extremism.

2 http://security.homeoffice.gov.uk/newspublications/publication-search/preventstrategy/
$1 \square$ need for colleges to play their role in fostering shared values and promoting cohesion. At the same time, colleges should focus on the risks of violent extremism which represents the greatest threat at the national level, while recognising that other forms of violence and extremism can and do manifest themselves within colleges and other training settings. We emphasised the importance of colleges assessing the particular risks and issues that they face and developing a proportionate response based around five key objectives:

to promote and reinforce shared values;

to create space for free and open debate; and to listen to and support mainstream voices;

to break down segregation amongst different student/learner communities including by supporting inter-faith and inter-cultural dialogue and understanding, and to engage all students/ learners in playing a full and active role in wider engagement in society;

to ensure student/learner safety and that colleges are free from bullying, harassment and intimidation;

to provide support for students/learners who may be at risk and appropriate sources of advice and guidance;

to ensure that students/learners and staff are aware of their roles and responsibilities in preventing violent extremism.

18 We believe that these objectives a useful framework for colleges and other providers to use across a wide range of local contexts and settings. 


\section{Support}

\section{$\Delta$ Support to individuals}

- Provide effective student support processes

- Raise staff awareness on key issues

- Form good links with police and other partners to share information

- Access external support from statutory or voluntary organisations

$\Delta$ Targeted activities related to preventing violent extremism

- Use curriculum to challenge extremist narratives

- Allow space for debate and increase staff confidence in discussing controversial issues

- Understand local issues and tensions with help from local authority and police

- Develop a network of community contacts and links with mentors and role models

\section{$\Delta$ Universal actions}

- Promote Every Child Matters outcomes, community cohesion, equalities and well-being

- Implement effective anti-bullying policies

- Focus on narrowing the attainment gap for all groups

- Encourage active citizenship and learner voice

- Links with families and local communities
$1 \bigcirc$ We see a clear need to distinguish between broad, universal action that strengthens the cohesion of communities and more targeted work to support those most vulnerable or actually at greatest risk. The diagram (left) shows how we see the relationship between these areas.

$20 \begin{aligned} & \text { This section describes how we } \\ & \text { intend to build on the existing }\end{aligned}$ resources, including developing more targeted support for those colleges that need this.

? 1 As part of our move towards a more $\angle$ self-regulating FE system we expect leadership for this area to be drawn from the sector, supported by the Learning and Skills Improvement Service (LSIS). We have established a Champion Principals group to oversee a programme of support and provide advice to Government (see Annex for membership of this group).

\section{$2 ?$ The Champion Principals group has $\triangle \triangle$ already begun to drive forward} work that will secure the support colleges need to help them navigate through and address the issues raised by this challenging agenda. The case studies provided in the Prevent Toolkit (see below) are based on their experiences.

33 We are also keen to work with the of colleges in promoting tolerance more generally. We have asked the Champions Group to review this area of activity with LSIS and develop some models of good practice, including procedures for learners to raise issues and concerns, that can be shared across the sector. 
24 A key source of support for colleges - will come from local partnership working. The Home Office and the Department for Communities and Local Government (CLG) are providing £13.8 million 'for a stronger civil response' against violent extremism, 'to disrupt radicalisers and support vulnerable individuals at a local level'. Local leaders will receive regular security briefings on violent extremism in their areas, and a Centre for Excellence for preventing violent extremism will be established. The Government also said it would be working to improve international links between anti-extremism practitioners. Colleges should discuss with their local authority partners if they wish to put in bids for any Preventing Violent Extremism funds and explore how they could contribute to local projects.

\section{Support available to all FE colleges}

$2 \sqsubset$ As the consultation document made $\checkmark \bigcirc$ clear, there is already a significant amount of support available for the broader, universal action. LSIS have brought this together in an accessible format, within the Excellence Gateway ${ }^{3}$.

3 http://excellence.qia.org.uk/ communitycohesion
This will be the 'one-stop shop' for all resources in this area. Currently the material includes guidance on community cohesion and the role of colleges in contributing towards more cohesive communities.

2 In parallel with issuing this
document, we are providing more
focused support for colleges engaged
in preventing extremism through a
Prevent Toolkit, which is now available on the Excellence Gateway and is being distributed to all colleges. This has been developed by DCSF, with help from the Association of Colleges. The Toolkit contains the following:

core information sections that can be used in staff training sessions;

tools to help review and build on the existing whole college strategies;

case studies to help institutions analyse their practice;

advice on the development of partnership working for the prevention of extremism;

links to further sources of information or support.

77 DCSF have produced a version of the $\angle 1$ Toolkit for schools which is being distributed through local authorities. Local authorities are also being asked to create locally tailored information describing their approach and giving details of the key contacts leading on different aspects - colleges are advised to contact the local authorities with which they work as much of the information will be directly relevant to the FE sector also. 


\section{Targeted support for colleges in priority areas}

28 The Champion Principals group

recommended that we focus particular support on those colleges in areas where the Office for Security and Counter-Terrorism has identified Prevent activity as a priority. They have offered to provide particular peer support to this group which will include:

a Prevent seminar in April 2009, reflecting the request from many respondents for opportunities to talk through these issues with others particularly those with more experience of dealing with this challenging agenda;

making themselves available to those working in colleges in identified priority areas if they face particular situations and need some advice.

\section{P The Home Office are also targeting $\triangle$ additional resource at police}

forces in these areas to enable them to build stronger partnerships with local schools, colleges and universities. This will enable local police liaison officers to establish contact and build relationships with appropriate staff and student representatives in colleges. As many colleges have told us, getting this relationship right is critical to handling any issues quickly and sensitively. We strongly encourage colleges to engage positively in a dialogue with the police.

\section{Other resources}

$\{$ There is also a wealth of material that has been developed, across Government, which colleges may find useful. This will be signposted through the Excellence Gateway. In particular:

cross-Government guidance was published in June 2008 for local partners on the Prevent agenda which acknowledges the role of colleges and encourages partnership working4;

the Association of Chief Police Officers have issued guidance for police forces emphasising the importance of police entering into an ongoing dialogue with staff and students in colleges to promote community cohesion, raise awareness about the Prevent agenda and encourage the exchange of information;

groups linked to Al-Qaida will often target recruitment efforts at Muslim students. While we know that the vast majority reject these extremist ideologies, colleges with significant numbers of Muslim students need to be aware of this risk and consider how they address the needs of this group. LSC research into the experience of Muslim students provides helpful background information about the particular issues faced by this group of students. As a result of this, they are providing a number of case studies, including text, photos and videos of successful Muslim role models on 'atypical' paths which are available as a resource.

\footnotetext{
4 http://security.homeoffice.gov.uk/newspublications/publication-search/preventstrategy/
} 


\section{Next steps}

\{ 1 Further work will be developed in coming months with key strands being:

DIUS has commissioned the Institute of Community Cohesion to identify areas for future support and development. This should culminate in the development of additional materials targeted at both FE and HE sectors, by end 2009;

the Home Office, DCSF and DIUS will be rolling out the 'Watch Over Me' DVD resource to all schools and colleges (available for free for three years). Please contact your local authority or police contact, or email community.cohesion@dcsf.gsi.gov.uk for more information;

whilst Ofsted are not including judgements on the prevention of violent extremism in their inspections it has made inspectors aware of the prevention of violent extremism in colleges and the Prevent strategy;

Becta is developing guidance on how colleges can support the safety of their students in the way they manage and provide IT services, which will be available in spring 2009. This will include a section on preventing individuals from being recruited by extremist groups. 


\section{Annex: Key contacts - Champion Principals Champion Principals group}

Paul Head (Chair) - Principal \& Chief Executive, College of North East London Michele Sutton - Principal, Bradford College

Ali Hadawi - Principal, Southend Adult Community College

Cathy Walsh - Principal, Barking College

Dr John Guy - Principal, Sixth Form College, Farnborough

Ian Clinton - Principal, Blackburn College

Nick Brown - Principal, Oldham Sixth Form College

Simon Kitchener - Principal, Luton Sixth Form College

Angela O’Donoghue - Principal, City of Sunderland College

\section{Other members of the group:}

Maggie Scott - Association of Colleges

Lynne Sedgmore - 157 Group

Sue Lakeman - Former Principal \& Chief Executive, Leyton Sixth Form College and Adviser to the group 

Department for

Innovation,

Universities \&

Skills

Printed in the UK on recycled paper with a minimum HMSO score of 75

First published February 2009

Department for Innovation,

Universities and Skills www.dius.gov.uk

URN 185-09-FE-b

(C) Crown Copyright 